\title{
Sofosbuvir and Ribavirin in Adolescents 12 to 17 Years Old With Hepatitis C Virus Genotype 2 or 3 Infection
}

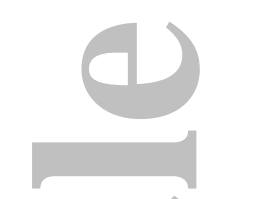

Short title: Sofosbuvir + Ribavirin in Adolescents With HCV

Stefan Wirth ${ }^{1}$, Philip Rosenthal ${ }^{2}$, Regino P. Gonzalez-Peralta ${ }^{3}$, Maureen M. Jonas ${ }^{4}$, William F. Balistreri ${ }^{5}$, Chuan-Hao Lin ${ }^{6}$, Winita Hardikar $^{7}$, Kathryn Kersey ${ }^{8}$, Benedetta Massetto ${ }^{8}$, Bittoo Kanwar ${ }^{8}$, Diana M. Brainard ${ }^{8}$, Jiang Shao $^{8}$, Evguenia Svarovskaia ${ }^{8}$, Brian Kirby ${ }^{8}$, Ronen Arnon ${ }^{9}$, Karen F. Murray ${ }^{10}$, and Kathleen B. Schwarz ${ }^{11}$

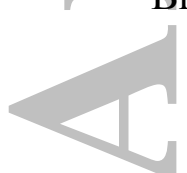

From the ${ }^{1}$ Helios Medical Center, Witten/Herdecke University, Wuppertal, Germany; ${ }^{2}$ University of California San Francisco, San Francisco, California, USA; ${ }^{3}$ University of Florida College of Medicine and Shands Children's Hospital, Gainesville, Florida, USA; ${ }^{4}$ Boston Children's Hospital, Boston, Massachusetts, USA;

${ }^{5}$ Cincinnati Children's Hospital Medical Center, Cincinnati, Ohio, USA; ${ }^{6}$ Children's Hospital Los Angeles, Los Angeles, California, USA; ${ }^{7}$ The Royal Children’s Hospital Melbourne, Victoria, Australia; ${ }^{8}$ Gilead Sciences, Inc., Foster City, California, USA; ${ }^{9}$ The Mount Sinai Hospital, New York, New York, USA; ${ }^{10}$ University of Washington School of Medicine and Seattle Children's Hospital, Seattle, Washington, USA; and ${ }^{11}$ Johns Hopkins University School of Medicine, Baltimore, Maryland, USA

Financial support: Funding for this study was provided by Gilead Sciences, Inc.

Abbreviations: ALT, alanine aminotransferase; AUC, area under the curve; BMI, body mass index; CV, coefficient of variation; eGFR, estimated glomerular filtration rate; GMR, geometric This is the author manuscript accepted for publication and has undergone full peer review but has not been through the copyediting, typesetting, pagination and proofreading process, which may lead to differences between this version and the Version record. Please cite this article as doi:10.1002/ hep.29278. 
mean ratio; $\mathrm{HCV}$, hepatitis $\mathrm{C}$ virus; INR, international normalized ratio of prothrombin time;

LLOQ, lower limit of quantification; RAS, resistance-associated substitution; RT-PCR, reverse transcription polymerase chain reaction; SOF, sofosbuvir; SVR, sustained virological response;

ULN, upper limit of normal.

Correspondence:

Stefan Wirth

Helios Medical Center

Department of Pediatrics

Witten-Herdecke University

Heusnerstr. 40

D-42283 Wuppertal

Phone: +492028963831

Email: +492028963834

Trial Registration: ClinicalTrials.gov NCT02175758.

\section{Author contributions:}

Kathryn Kersey, Bittoo Kanwar, and Diana M. Brainard contributed to the study design.

Stefan Wirth, Philip Rosenthal, Regino Peralta-Gonzalez, Maureen M. Jonas, William F.

Balistreri, Chuan-Hao Lin, Winita Hardikar, Ronen Arnon, Karen F. Murray, Kathleen Schwarz served as investigators in this study. Benedetta Massetto, Jiang Shao, Evguenia Svarovskaia and Brian Kirby contributed to the data interpretation. All authors contributed to the writing and review of the report.

Writing assistance: Jennifer King, $\mathrm{PhD}$, of August Editorial helped draft the manuscript, funded by Gilead Sciences, Inc.

Role of the Study Sponsor: The sponsor (Gilead Sciences) collected the data, monitored the study conduct, and performed the statistical analyses. 


\section{Conflicts of Interest:}

Stefan Wirth has served as an investigator for Gilead, AbbVie, and Roche.

Philip Rosenthal has received grant support from Gilead, AbbVie, BMS, Roche, and Retrophin, and serves as a consultant to Gilead, AbbVie, Audentes, Intercept, Alexion, Retrophin, and Albireo, and serves as a speaker for Retrophin.

Regino Peralta-Gonzalez receives grant support from Gilead, and AbbVie, and serves on advisory boards for Genetech-Roche.

Maureen M. Jonas receives grant support from Bristol Myers Squibb, Roche, Gilead, AbbVie, and Echosens, and serves as a consultant for Gilead.

William F. Balistreri receives grant support from Gilead..

Chuan-Hao Lin receives grant support from Gilead.

Karen F. Murray receives grant support from Gilead and Shire, and holds stock in Merck.

Kathleen Schwarz receives grant support from Gilead, Bristol Myers Squibb, and Roche, and serves as a consultant for Gilead and Roche.

Kathryn Kersey, Benedetta Massetto, Bittoo Kanwar, Diana M. Brainard, Jiang Shao, Evguenia Svarovskaia, and Brian Kirby are employees of Gilead and hold stock in the company.

Winita Hardikar and Ronen Arnon declare no conflicts of interest. 


\section{ABSTRACT [268/260 words]}

Background \& Aims. Children with chronic hepatitis C virus (HCV) infection have limited treatment options. We evaluated the all-oral combination of sofosbuvir and ribavirin in adolescents aged 12-17 with HCV genotype 2 or 3.

Methods. Fifty-two patients received sofosbuvir 400mg once daily and weight-based ribavirin twice daily for 12 (genotype 2) or 24 (genotype 3 ) weeks. The pharmacokinetics of sofosbuvir and its metabolite GS-331007 were evaluated by intensive plasma sampling at day 7 in the first 10 patients enrolled, and by sparse sampling in all patients throughout treatment. The primary efficacy endpoint was the percentage of patients with a sustained virologic response 12 weeks after treatment (SVR12).

Results. The median age of patients was 15 years, and 75\% had genotype 3. Eighty-three percent of patients were treatment-naïve, and $73 \%$ were infected by vertical transmission. Forty percent were assessed as not having cirrhosis; the remainder did not have a cirrhosis determination. Overall, SVR12 was achieved by $98 \%$ of patients $(51 / 52 ; 95 \%$ CI, 90\%-100\%). SVR12 rates were 100\% (13/13) for patients with genotype 2 and 97\% (38/39) for genotype 3 . The single patient who did not achieve SVR12 was lost to follow-up after achieving SVR4. The most commonly reported adverse events were nausea (27\%) and headache (23\%). When compared with the exposure in adults treated in Phase 2 and 3 sofosbuvir studies, the $\mathrm{AUC}_{\text {tau }}$ and $\mathrm{C}_{\max }$ for sofosbuvir and GS-331007 in adolescents were within predefined pharmacokinetic equivalence boundaries of $50 \%-200 \%$.

Conclusion. Sofosbuvir and ribavirin was safe and highly effective in adolescents with chronic HCV genotype 2 or 3 infection. ClinicalTrials.gov NCT02175758.

Keywords: direct-acting antiviral; pediatrics; polymerase inhibitor; pharmacokinetics 


\section{INTRODUCTION}

Estimates of hepatitis C virus (HCV) seroprevalence in children and adolescents vary globally. In Europe and the United States, the prevalence is generally low, with estimates of up to $0.4 \%,{ }^{1}$ although an increase has been reported recently among adolescents in the United States due to opioid abuse. ${ }^{2,3}$ In contrast, in some other countries, for example Egypt, the estimated $\mathrm{HCV}$ seroprevalence rate in children is higher, up to $6 \% .{ }^{4}$ The presentation of HCV infection in pediatric patients is largely either without symptoms or with mild, non-specific symptoms. However a minority of cases may develop signs and symptoms of more advanced liver disease with significant fibrosis or cirrhosis on liver biopsy; ${ }^{5,6}$ a minority of young patients develop hepatocellular carcinoma and end-stage liver disease necessitating liver transplantation. ${ }^{7,8}$

Currently, children with chronic HCV infection have fewer treatment options than adults do. The current standard of care for chronic HCV in the pediatric population is treatment for 24 or 48 weeks with interferon or peginterferon and ribavirin, a regimen which requires subcutaneous injections and is associated with significant side effects, including growth impairment. ${ }^{9,10}$ In contrast, standard of care for chronic HCV in adults includes several all-oral regimens with direct-acting antivirals specifically targeting HCV that are highly effective and have a favorable safety profile. ${ }^{11,12}$

Peginterferon and ribavirin treatment has been associated with high rates of success in children and adolescents with HCV genotype 2 or 3 infection. In pooled data from 5 studies, $93 \%$ of 73 children with HCV genotype 2 or 3 achieved sustained virologic response (SVR) with 24 weeks of peginterferon and ribavirin. ${ }^{13-17}$ Response is durable, as indicated by a follow-up study of 21 responders 4 to 7 years after treatment. ${ }^{18}$ However, because of the potential for tolerability issues and growth impairment with peginterferon and ribavirin, there is no universal 
consensus on when or if to treat chronic HCV infection in children with these agents. It has been suggested that most children with chronic HCV infection should defer treatment until interferonfree regimens are available. ${ }^{19}$ Expanding HCV treatment options to include all-oral, directacting antiviral regimens in children and adolescents could improve accessibility to treatment worldwide. We evaluated the safety and effectiveness of combination therapy with sofosbuvir, a potent oral HCV NS5B polymerase inhibitor, in combination with weight-based ribavirin in adolescents aged 12 to 17 years old with HCV genotype 2 or 3 chronic infection. The combination of sofosbuvir and ribavirin has shown high rates of sustained virologic response in adults when administered for 12 weeks in those with HCV genotype 2 infection and 24 weeks in those with HCV genotype 3 infection. ${ }^{20-22}$ Therefore, in this study, the treatment duration was 12 weeks for patients with HCV genotype 2 and 24 weeks for those with HCV genotype 3 . The pharmacokinetics of sofosbuvir and GS-331007, the primary metabolite of sofosbuvir, were evaluated and compared with data from HCV-infected adults.

\section{METHODS}

\section{Patients}

Eligible patients were 12 to $<18$ years old and had chronic infection with HCV genotype 2 or 3 , with plasma HCV RNA levels $\geq 10^{4} \mathrm{IU} / \mathrm{mL}$. Patients were either HCV treatment naïve or experienced. Patients with or without cirrhosis were eligible; a liver biopsy was not required for study entry. Patients were required to have an absolute neutrophil count $\geq 1,500 / \mathrm{mm}^{3}$ and a hemoglobin level of $\geq 11 \mathrm{~g} / \mathrm{dL}$ for females and $\geq 12 \mathrm{~g} / \mathrm{dL}$ for males. Patients were excluded from participating in the study if they had any of the following conditions: decompensated liver 
disease; chronic liver disease of a non-HCV etiology; alpha-fetoprotein level >50 ng/mL; serum creatinine $>1.5 \mathrm{mg} / \mathrm{dL}$; estimated glomerular filtration rate (eGFR) $<90 \mathrm{~mL} / \mathrm{min} / 1.73 \mathrm{~m}^{2}$ as calculated by the Schwartz Formula; evidence of hepatocellular carcinoma or other malignancy; infection with hepatitis A virus, hepatitis B virus , or HIV; significant cardiovascular, pulmonary, or neurological disease; evidence of a malabsorption syndrome that could interfere with absorption of orally administered medications; history of solid organ or bone marrow transplantation; systemic corticosteroid use for $\geq 5$ days (pulmonary/nasal administration was permitted); clinically relevant alcohol or drug abuse within 12 months of screening; or psychiatric hospitalization, suicide attempt, or disability resulting from psychiatric illness within the prior 5 years. Parents or legal guardians provided written informed consent before patients undertook any study-related procedures. Patients who could read and write provided written assent.

\section{Study Design}

This was a Phase 2, multi-center, open-label study. The study treatment was sofosbuvir $400 \mathrm{mg}$ once daily, the same dose as in adults, and weight-based ribavirin (Table 1) twice daily. Weightbased ribavirin dosing instructions were based on a combination of the prescribing information and the summary of product characteristics (Rebetol, Merck). ${ }^{23,24}$ Treatment was administered for 12 weeks in patients with HCV genotype 2 infection and 24 weeks in those with HCV genotype 3 infection. The first ten patients enrolled in the study underwent an intensive pharmacokinetic evaluation on the seventh day of dosing. To be eligible for the pharmacokinetic evaluation, patients had to weigh $\geq 45 \mathrm{~kg}$ and be naïve to $\mathrm{HCV}$ treatment. Patients received sofosbuvir plus ribavirin during the initial seven-day pharmacokinetic lead-in. After completing the pharmacokinetic lead-in phase, patients were immediately enrolled into the treatment phase 
with no interruption of study drug administration. All patients were to complete follow-up visits at post-treatment weeks 4, 12, and 24 .

The study protocol was approved by the review board or ethics committee of each institution prior to study initiation. The study was conducted in accordance with the International Conference on Harmonization Good Clinical Practice Guidelines and the Declaration of Helsinki. The sponsor (Gilead Sciences) collected the data, monitored the study conduct, and performed the statistical analyses. All authors had access to the study data and had reviewed and approved the final manuscript.

\section{Efficacy Evaluation}

Blood samples for determining plasma HCV RNA levels were drawn at screening; on day 1 of treatment; at treatment weeks 1, 2, 4, 8, 12 for all patients and in addition at treatment weeks 16, 20, and 24 for patients receiving 24 weeks of treatment; and at follow-up weeks 4, 12, and 24 . HCV RNA levels were quantified by using the Roche COBAS Ampliprep/COBAS TaqMan HCV Test, v2.0 (Roche Molecular Systems, Inc., Branchburg, NJ), which has a lower limit of quantification (LLOQ) of $15 \mathrm{IU} / \mathrm{mL}$.

The primary efficacy endpoint was the percentage of patients who achieved SVR12, defined as having a plasma HCV RNA level < LLOQ (15 IU/mL) 12 weeks after discontinuing study drugs. The null $(\mathrm{H} 0, \mathrm{SVR} 12=80 \%)$ and alternative $(\mathrm{H} 1, \mathrm{SVR} 12 \neq 80 \%)$ hypotheses were used to compare the SVR12 rate of sofosbuvir plus ribavirin with the historical rate of $80 \%$ in adolescent patients treated with peginterferon plus ribavirin. The SVR12 rate was compared with the historical SVR12 rate of $80 \%$ using a 2-sided exact 1-sample binomial test at the 0.05 significance level. The 2 -sided $95 \%$ exact CI based on the Clopper-Pearson method was provided for the SVR12 rate. 
For patients with missing efficacy data (HCV RNA values), if the missing data was preceded and followed by values that were deemed successes (HCV RNA < LLOQ target not detectable), then the missing data point was termed a success.

\section{Safety Evaluations}

Complete physical examinations were conducted on day 1 of treatment and at the final treatment visit. During treatment, data regarding vital signs, reported adverse events, concomitant medication intake, and clinical laboratory tests were collected at every visit. At all follow-up visits, vital signs and reported adverse events were collected, and symptom-directed physical examinations were done. Concomitant medications were reported at the follow-up week 4 visit, and clinical laboratory tests were done at the follow-up week 4 and 12 visits. The Medical Dictionary for Regulatory Activities (MedDRA), version 19.1, was used to code treatment-emergent clinical and laboratory adverse events.

At baseline, all patients underwent a Tanner pubertal stage assessment. Patients who had achieved Tanner stage 5 at baseline had no further Tanner staging. Those who scored below Tanner 5 underwent additional Tanner assessments at the final treatment visit and at follow-up weeks 12 and 24.

\section{Pharmacokinetic Analyses}

At the Day 7 visit, serial pharmacokinetic blood samples were collected from the first 10 patients enrolled in the study to determine the pharmacokinetics of sofosbuvir and its primary metabolite, GS-331007. Patients arrived for their Day 7 visit in a fasted state (no food or drink except water at least 8 hours prior to the visit), and were instructed not to have taken their Day 7 dose of study drug. A pre-dose blood sample was collected up to 30 minutes prior to Day 7 dosing, after which 
patients were provided with a standardized meal containing approximately 400 calories (kcal) and 13 grams of fat. Within five minutes after consuming the standardized meal, patients were dosed with sofosbuvir and ribavirin. Post-dose blood samples were collected at $0.5,1,2,3,4,8$, and 12 hours post-dose (with pre-dose also serving as $\mathrm{t}=24$ ).

Upon confirmation of the appropriateness of the 400-mg sofosbuvir dose in the first 10 adolescents, the remainder of patients was enrolled in the study. For all enrolled patients, sparse pharmacokinetic samples (single plasma samples) were collected at all scheduled on-treatment study visits.

The sofosbuvir and GS-331007 data from intensive and sparse blood samples collected in this study were utilized to estimate pharmacokinetic parameters $\left(\mathrm{AUC}_{\mathrm{tau}}\right.$, [area under the curve] and $\mathrm{C}_{\max }$,[maximum concentration]) by population pharmacokinetic modeling. These exposures were compared to integrated adult data from Phase 2 and 3 clinical studies of sofosbuvir using an analysis of variance. The $90 \%$ confidence intervals were constructed for the percent ratio of geometric means of pharmacokinetic parameters $\mathrm{AUC}_{\text {tau }}$ and $\mathrm{C}_{\max }$ with equivalence boundaries were set as $50 \%$ to $200 \%$.

\section{Resistance Monitoring}

Plasma samples for viral sequencing were collected at all visits during treatment and follow-up, following the same schedule as for HCV RNA evaluation. The HCV NS5B coding region was amplified by DDL Diagnostic Laboratory (Rijswijk, Netherlands) using standard reverse transcription polymerase chain reaction (RT-PCR) technology. Following amplification, PCR products were deep sequenced with an assay cutoff of $15 \%$. Resistance-associated substitutions (RASs) were reported if present in more than $15 \%$ of the sequence reads. NS5B nucleoside 
inhibitor RASs were defined as follows: S96T, N142T, L159F, E237G, S282any, M/F289L/I, $\mathrm{L} 320 \mathrm{~F} / \mathrm{I} / \mathrm{V}$, and $\mathrm{V} 321 \mathrm{~A} / \mathrm{I}$.

\section{RESULTS}

\section{Patient Population}

From October 2014 to June 2015, 52 patients, 39 (75\%) GT3 and 13 (25\%) GT2, were enrolled at 30 study sites in Australia, Germany, Italy, New Zealand, Russia, the United Kingdom, and the United States. The median age for the study population was 15 years (Table 2), and the majority was treatment naïve $(43,83 \%)$ and infected through vertical transmission $(38,73 \%)$. Sixty percent of patients were male, and $90 \%$ were white. Sixty-three percent had a non-CC IL$28 B$ genotype. No patients had documented cirrhosis; 21 patients $(40 \%)$ were assessed as not cirrhotic, and in the remaining 31 patients $(60 \%)$ no cirrhosis assessment was performed.

All 52 patients completed treatment (Figure 1). One patient with HCV genotype 3 was lost to follow up after having completed the follow-up week 4 visit.

\section{Virologic Response}

Overall, $98 \%$ of patients reached SVR12 (51/52; 95\% CI, 90\% to 100\%) (Table 3). All 13 patients with HCV genotype 2 achieved SVR12 (100\%; 95\% CI, 75\% to 100\%). Ninety-seven percent of patients with HCV genotype 3 achieved SVR12 (38/39, 95\% CI, 87\%-100\%). Of the 9 treatment-experienced patients in the study, $100 \%(95 \% \mathrm{CI}, 66 \%$ to $100 \%)$ achieved SVR 12. No patients had virologic nonresponse. The single patient who did not achieve SVR12 had HCV RNA $<$ LLOQ at follow-up week 4 (SVR4) but was lost to follow-up before completing the follow-up week 12 visit. The high overall SVR12 rate, with no cases of virologic nonresponse, 
precludes meaningful interpretation of subgroup analyses.

\section{Safety}

The two most commonly reported adverse events were nausea and headache, reported by $27 \%$ and $23 \%$ of patients, respectively (Table 4 ). Among patients receiving 12 weeks of treatment, $92 \%$ experienced an adverse event and $77 \%$ of those receiving 24 weeks of treatment experienced an adverse event. Serious adverse events were not reported for any patients. No patients discontinued treatment because of an adverse event. Two patients had ribavirin dosing reduced, 1 patient due to influenza infection, which was considered unrelated to study treatment by the investigator, and a second patient because of nausea and vomiting, which were considered related to study treatment by the investigator.

Except for one, all adverse events were mild or moderate in intensity. A patient receiving 24 weeks of treatment had a Grade 3 (severe) joint injury (shoulder trauma), which was not considered serious or related to study drug by the investigator.

Reductions in hemoglobin levels were observed in 3 patients, a finding consistent with the expected hemolytic anemia associated with ribavirin treatment. The decrease was in all cases isolated, followed by return to normal or baseline value by the posttreatment follow-up; none of the patients had a hemoglobin value lower than $10 \mathrm{~g} / \mathrm{dL}$. In one of these patients, a transient increase in serum total bilirubin was observed to have a temporal relationship with reductions in hemoglobin. A second patient, with a medical history of Gilbert's syndrome and jaundice at study screening, experienced elevated indirect bilirubin throughout the treatment period.

Although limited to 12 weeks of follow-up, study treatment did not appear to have any notable effect on development as assessed by Tanner pubertal staging. At end of treatment and week 12 of follow-up, all patients had no change or had an increase from baseline in their Tanner 
stage for pubic hair and genitalia development.

\section{Pharmacokinetics}

Administration of sofosbuvir $400 \mathrm{mg}$ in $\mathrm{HCV}$-infected adolescents provided plasma exposures (AUCtau and Cmax) of sofosbuvir and GS-331007 comparable to those observed in adults from Phase 2 and 3 studies as the $90 \%$ confidence intervals of the percent geometric mean ratios were within the predefined pharmacokinetic equivalence boundaries of $50 \%$ to $200 \%$ (Table 5).

\section{Resistance Analyses}

NS5B deep sequencing results were obtained for 48 of 49 patients with virologic outcome data.

For the remaining patient, baseline amplification of NS5B failed. At a 15\% cutoff, no NS5B nucleoside RASs was detected in any patient. No on-treatment breakthrough or relapse was observed in any patients through post-treatment Week 12 . Therefore, not post-baseline resistance testing was performed. 


\section{DISCUSSION}

Curing HCV in young patients — prior to their entry into childbearing years — is an important component of reducing transmission of $\mathrm{HCV}$ in the whole population, because vertical transmission is currently the most common mode of chronic infection in children. ${ }^{10}$ This is the first reported study of an all-oral regimen containing a direct-acting antiviral in adolescent patients with chronic HCV genotype 2 or 3 infection.

Overall, $98 \%$ of adolescents treated with sofosbuvir plus ribavirin for 12 or 24 weeks achieved SVR12. Response rates were high in both HCV genotype 2 patients with 100\% (13/13) achieving SVR12, and in HCV genotype 3 patients with 97\% (38/39) achieving SVR12. The single patient who did not achieve SVR12 in this study achieved SVR4 but was subsequently lost to follow-up.

Response rates in adolescents were higher than those reported in adults treated with sofosbuvir plus ribavirin, and the differences were more substantial for HCV genotype 3 infection. In adults with chronic HCV genotype 2 infection, 12 weeks of sofosbuvir and ribavirin have led to SVR12 rates ranging from $86 \%$ in treatment-experienced ${ }^{25}$ to $97 \%$ in treatment-naïve patients. ${ }^{20,21}$ In adults with chronic HCV genotype 3 infection, 24 weeks of treatment with sofosbuvir and ribavirin resulted in SVR12 rates of 94\% in treatment-naïve and $79 \%$ in treatment experienced patients. ${ }^{21}$ While the presence of cirrhosis does not impact the efficacy of sofosbuvir and ribavirin in $\mathrm{HCV}$ genotype 2 patients, ${ }^{22}$ prior treatment and cirrhosis lowers likelihood of response in patients with HCV genotype 3 infection, with an SVR12 rate of $62 \%$ in treatmentexperienced HCV genotype 3 patients with cirrhosis. ${ }^{21}$ Although $17 \%$ of the adolescents in our study were treatment experienced, none were known to have cirrhosis. The generally mild course 
of disease in children may account in part for the higher response rate in patients with HCV genotype 3 in this study.

Based on our analysis of adolescents, the pharmacokinetic profile of sofosbuvir is similar to that reported in adults and consistent with the profile of sofosbuvir in combination with the HCV NS5A inhibitor ledipasvir in adolescents with HCV genotype 1 infections. $^{26}$

In this study, adverse events were generally mild and consistent with those reported in prior studies of sofosbuvir and ribavirin in adults. ${ }^{20-22}$ A small minority of patients receiving 24 weeks of sofosbuvir and ribavirin experienced transient, mild reductions in hemoglobin, consistent with the toxicity profile of ribavirin. Notably, based on Tanner pubertal staging, treatment with sofosbuvir plus ribavirin for 12 or 24 weeks did not affect short-term development. Overall the safety profile of SOF+RBV represents an advantage comparing to the current standard of care represented by peginterferon and ribavirin. ${ }^{10,16}$

Limitations of this study include a relatively small sample size and an incomplete cirrhosis assessment of the patients, $60 \%$ of whom were not evaluated for cirrhosis. Therefore, it is unclear whether cirrhosis affects the response to sofosbuvir and ribavirin in adolescents.

In summary, sofosbuvir and ribavirin was well tolerated and highly effective in treating adolescents with chronic HCV genotype 2 or 3 infection. Sofosbuvir in combination with ribavirin will provide an important option for treating chronic $\mathrm{HCV}$ infection in the pediatric population. 


\section{ACKNOWLEDGMENTS}

We thank the patients and their families as well as the study-site personnel. Jennifer King, PhD, of August Editorial helped draft the manuscript.

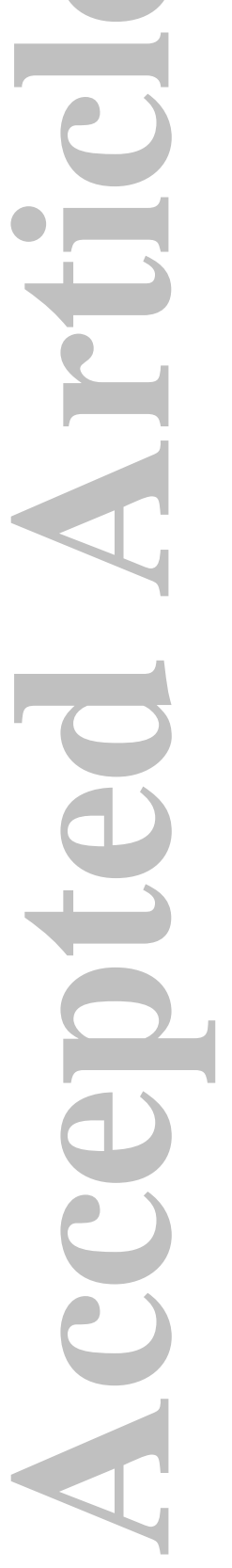




\section{References}

1. El-Shabrawi MH, Kamal NM. Burden of pediatric hepatitis C. World J Gastroenterol 2013;19:7880-7888.

2. Suryaprasad AG, White JZ, Xu F, et al. Emerging epidemic of hepatitis $\mathrm{C}$ virus infections among young nonurban persons who inject drugs in the United States, 2006-2012. Clin Infect Dis 2014;59:1411-1419.

3. Zibbell JE, Iqbal K, Patel RC, et al. Increases in hepatitis $\mathrm{C}$ virus infection related to injection drug use among persons aged $\leq 30$ years - Kentucky, Tennessee, Virginia, and West Virginia, 2006-2012. MMWR Morb Mortal Wkly Rep 2015;64:453-458.

4. Frank C, Mohamed MK, Strickland GT, et al. The role of parenteral antischistosomal therapy in the spread of hepatitis C virus in Egypt. Lancet 2000;355:887-891.

5. El-Hawary MA, El-Raziky MS, Esmat G, et al. Assessment of hepatic fibrosis in pediatric cases with hepatitis C virus in Egypt. World J Gastroenterol 2007;13:2846-2851.

6. Goodman ZD, Makhlouf HR, Liu L, et al. Pathology of chronic hepatitis C in children: liver biopsy findings in the Peds-C Trial. Hepatology 2008;47:836-843.

7. Barshes NR, Udell IW, Lee TC, et al. The natural history of hepatitis C virus in pediatric liver transplant recipients. Liver Transpl 2006;12:1119-1123.

8. González-Peralta RP, Langham MR Jr, Andres JM, et al. Hepatocellular carcinoma in 2 young adolescents with chronic hepatitis C. J Pediatr Gastroenterol Nutr 2009;48:630-5.

9. Jonas MM, Balistreri W, Gonzalez-Peralta RP, et al. Pegylated interferon for chronic hepatitis $\mathrm{C}$ in children affects growth and body composition: results from the pediatric study of hepatitis C (PEDS-C) trial. Hepatology 2012;56:523-531.

10. Wirth S. Current treatment options and response rates in children with chronic hepatitis C. World J Gastroenterol 2012;18:99-104.

11. AASLD/IDSA HCV Guidance Panel. Hepatitis C guidance: AASLD-IDSA recommendations for testing, managing, and treating adults infected with hepatitis $\mathrm{C}$ virus. Hepatology 2015;62:932-954.

12. European Association for the Study of the Liver. EASL Recommendations on Treatment of Hepatitis C 2016. J Hepatol 2017;66:153-194.

13. Wirth S, Pieper-Boustani H, Lang T, et al. Peginterferon alfa-2b plus ribavirin treatment in children and adolescents with chronic hepatitis C. Hepatology 2005;41:1013-1018.

14. Jara P, Hierro L, Vega A de la, et al. Efficacy and safety of peginterferon-alpha2b and ribavirin combination therapy in children with chronic hepatitis $\mathrm{C}$ infection. Pediatr Infect Dis J 2008;27:142-148. 
5. Wirth S, Ribes-Koninckx C, Calzado MA, et al. High sustained virologic response rates in children with chronic hepatitis $\mathrm{C}$ receiving peginterferon alfa-2b plus ribavirin. J Hepatol 2010;52:501-507.

6. Sokal EM, Bourgois A, Stéphenne X, et al. Peginterferon alfa-2a plus ribavirin for chronic hepatitis $\mathrm{C}$ virus infection in children and adolescents. J Hepatol 2010;52:827-831.

7. Schwarz KB, Gonzalez-Peralta RP, Murray KF, et al. The combination of ribavirin and peginterferon is superior to peginterferon and placebo for children and adolescents with chronic hepatitis C. Gastroenterology 2011;140:450-458.e1.

8. Schwarz KB, Molleston JP, Jonas MM, et al. Durability of Response in Children Treated With Pegylated Interferon alfa [corrected] $2 \mathrm{a} \pm$ Ribavirin for Chronic Hepatitis C. J Pediatr Gastroenterol Nutr 2016;62:93-96.

9. Lee CK, Jonas MM. Treating HCV infection in children. Clinical Liver Disease 2015;5:1416.

0. Lawitz E, Mangia A, Wyles D, et al. Sofosbuvir for previously untreated chronic hepatitis C infection. N Engl J Med 2013;368:1878-1887.

1. Zeuzem S, Dusheiko GM, Salupere R, et al. Sofosbuvir and ribavirin in HCV genotypes 2 and 3. N Engl J Med 2014;370:1993-2001.

2. Foster GR, Pianko S, Brown A, et al. Efficacy of Sofosbuvir Plus Ribavirin With or Without Peginterferon-Alfa in Patients With Hepatitis C Virus Genotype 3 Infection and Treatment-Experienced Patients With Cirrhosis and Hepatitis C Virus Genotype 2 Infection. Gastroenterology 2015;149:1462-1470.

3. Rebetol (ribavirin) capsules: US prescribing information. Whitehouse Station, NJ: Merck, 2003 (https://www.merck.com/product/usa/pi_circulars/r/rebetol_pi.pdf).

4. Rebetol (ribavirin) capsules: Summary of Product Characteristics. Hertfordshire, England: Merck Sharp \& Dohme Limited, 2013.

5. Jacobson IM, Gordon SC, Kowdley KV, et al. Sofosbuvir for hepatitis C genotype 2 or 3 in patients without treatment options. N Engl J Med 2013;368:1867-1877.

6. Balistreri WF, Murray KF, Rosenthal P, et al. The safety and effectiveness of ledipasvirsofosbuvir in adolescents 12 to 17 years old with hepatitis $\mathrm{C}$ virus genotype 1 infection. Hepatology 2016;E-pub ahead of print. 


\section{TABLES AND FIGURES}

Table 1. Ribavirin Dosing and Administration

Table 2. Patient Demographics and Baseline Characteristics

Table 3. Treatment Response to Sofosbuvir and Ribavirin

Table 4. Adverse Events and Laboratory Abnormalities

Table 5. Mean (\%CV) Sofosbuvir and GS-331007 Exposures

Figure 1. Patient Disposition. HCV, hepatitis C virus; RBV, ribavirin; SOF, sofosbuvir.

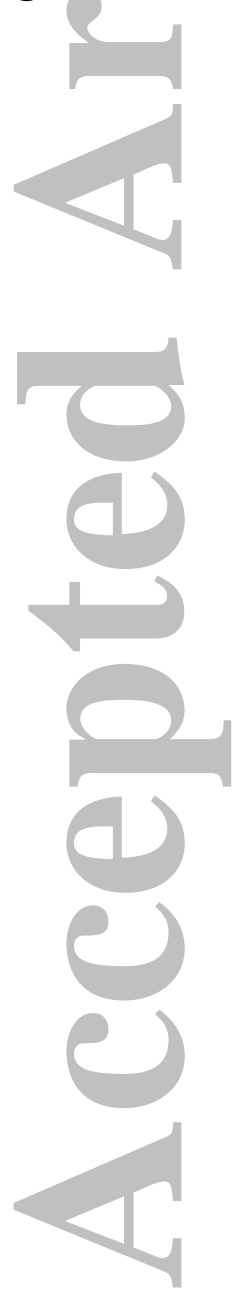


Table 1. Ribavirin Dosing and Administration

\begin{tabular}{|c|c|c|}
\hline Body Weight, kg & Ribavirin Daily Dose & No. of Capsules \\
\hline$<47$ & $15 \mathrm{mg} / \mathrm{kg} / \mathrm{day}$ & $\begin{array}{l}\text { Oral solution. Divided dose in } \\
\text { morning and evening. }\end{array}$ \\
\hline $47-49$ & 600 mg/day & $\begin{array}{l}1 \times 200-m g \text { capsules AM } \\
2 \times 200-m g \text { capsules PM }\end{array}$ \\
\hline $50-65$ & 800 mg/day & $\begin{array}{l}2 \times 200-m g \text { capsules AM } \\
2 \times 200-m g \text { capsules PM }\end{array}$ \\
\hline $66-80$ & $1,000 \mathrm{mg} /$ day & $\begin{array}{l}2 \times 200-m g \text { capsules AM } \\
3 \times 200-m g \text { capsules PM }\end{array}$ \\
\hline $81-105$ & $1,200 \mathrm{mg} /$ day & $\begin{array}{l}3 \times 200-m g \text { capsules AM } \\
3 \times 200-m g \text { capsules PM }\end{array}$ \\
\hline$>105$ & $1,400 \mathrm{mg} /$ day & $\begin{array}{l}3 \times 200-m g \text { capsules AM } \\
4 \times 200-m g \text { capsules PM }\end{array}$ \\
\hline
\end{tabular}

${ }^{a}$ For patients of any weight who were unable or unwilling to take ribavirin capsules, oral solution could be used at $15 \mathrm{mg} / \mathrm{kg} /$ day divided morning and evening.

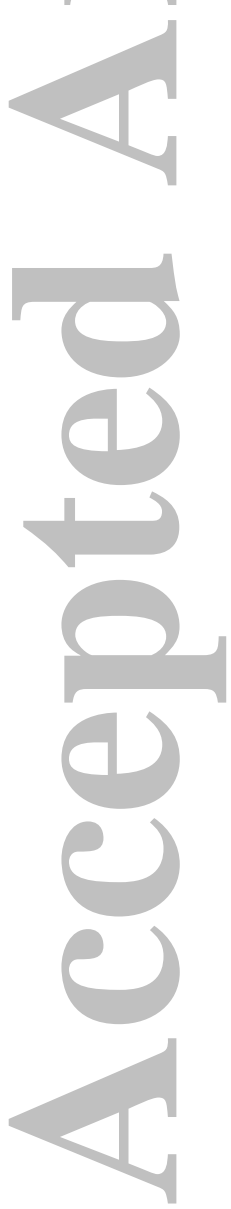


Table 2. Patient Demographics and Baseline Characteristics

\begin{tabular}{|c|c|c|c|}
\hline & $\begin{array}{c}\text { HCV Genotype } 2 \\
\text { SOF+RBV 12 Weeks } \\
(n=13)\end{array}$ & $\begin{array}{c}\text { HCV Genotype } 3 \\
\text { SOF+RBV } 24 \text { Weeks } \\
(n=39)\end{array}$ & $\begin{array}{c}\text { Total } \\
(\mathrm{N}=52)\end{array}$ \\
\hline Median (range) age, yr. & $14(12,17)$ & $15(12,17)$ & $15(12,17)$ \\
\hline Male, $\mathrm{n}(\%)$ & $8(62)$ & $23(59)$ & $31(60)$ \\
\hline \multicolumn{4}{|l|}{ Race, n (\%) } \\
\hline White & $11(85)$ & $36(92)$ & $47(90)$ \\
\hline Black or African American & $2(15)$ & 0 & $2(4)$ \\
\hline Asian & 0 & $1(3)$ & $1(2)$ \\
\hline Hawaiian or Pacific Islander & 0 & $1(3)$ & $1(2)$ \\
\hline Other & 0 & $1(3)$ & $1(2)$ \\
\hline Median (range) BMI, $\mathrm{kg} / \mathrm{m}^{2}$ & $21(16,28)$ & $22(16,32)$ & $22(16,32)$ \\
\hline \multicolumn{4}{|l|}{ Genotype, n (\%) } \\
\hline 2 & $6(46)$ & 0 & $6(12)$ \\
\hline $2 b$ & $5(39)$ & 0 & $5(10)$ \\
\hline $2 a / 2 c$ & $2(15)$ & 0 & $2(4)$ \\
\hline 3 & 0 & $1(3)$ & $1(2)$ \\
\hline $3 a$ & 0 & 38 (97) & $38(73)$ \\
\hline Mean (SD) HCV RNA, $\log _{10} \mathrm{IU} / \mathrm{mL}$ & $5.9(0.98)$ & $6.2(0.77)$ & $6.1(0.83)$ \\
\hline HCV RNA $\geq 800,000 \mathrm{IU} / \mathrm{mL}, \mathrm{n}(\%)$ & $8(62)$ & $26(67)$ & $34(65)$ \\
\hline \multicolumn{4}{|l|}{ Response to prior HCV treatment, $\mathrm{n}(\%)$} \\
\hline Nonresponder & 0 & $6(15)$ & $6(12)$ \\
\hline Relapse/breakthrough & 0 & $2(5)$ & $2(4)$ \\
\hline Interferon intolerant & 0 & $1(3)$ & $1(2)$ \\
\hline \multicolumn{4}{|l|}{$I L-28 B, \mathrm{n}(\%)$} \\
\hline $\mathrm{CC}$ & $3(23)$ & $16(41)$ & $19(37)$ \\
\hline CT & $9(69)$ & $21(54)$ & $30(58)$ \\
\hline $\mathrm{TT}$ & $1(8)$ & $2(5)^{\prime}$ & $3(6)^{\prime}$ \\
\hline \multicolumn{4}{|l|}{ Cirrhosis, $\mathrm{n}(\%)$} \\
\hline No & $4(31)$ & $17(44)$ & $21(40)$ \\
\hline Unknown & $9(69)$ & $22(56)$ & $31(60)$ \\
\hline Mean (SD) ALT, U/L & $37(25.1)$ & $60(57.5)$ & $54(52.2)$ \\
\hline Mean (SD) eGFR, ${ }^{a}\left(\mathrm{~mL} / \mathrm{min} / 1.73 \mathrm{~m}^{2}\right)$ & $147.5(25.2)$ & $151.3(25.4)$ & $150.3(25.1)$ \\
\hline \multicolumn{4}{|l|}{ Mode of HCV infection, $\mathrm{n}(\%)^{\mathrm{b}}$} \\
\hline Vertical transmission & $8(62)$ & $30(77)$ & $38(73)$ \\
\hline Unknown & $5(38)$ & $4(10)$ & $9(17)$ \\
\hline Blood product transfusion & 0 & $5(13)$ & $5(10)$ \\
\hline Contaminated needle or IV drug use & $1(8)$ & 0 & $1(2)$ \\
\hline Surgery/operation & 0 & $1(3)$ & $1(2)$ \\
\hline
\end{tabular}

${ }^{\mathrm{a}}$ Estimated using the Schwartz Formula.

${ }^{\mathrm{b}}$ Patients may have multiple modes of HCV infection.

ALT, alanine aminotransferase; BMI, body mass index; eGFR, estimated glomerular filtration rate; HCV, hepatitis C virus; IV, intravenous; RBV, ribavirin; SOF, sofosbuvir. 
Table 3. Treatment Response to Sofosbuvir and Ribavirin

\begin{tabular}{|c|c|c|c|}
\hline & $\begin{array}{c}\text { HCV Genotype } 2 \\
\text { SOF+RBV } 12 \text { Weeks } \\
(n=13)\end{array}$ & $\begin{array}{c}\text { HCV Genotype } 3 \\
\text { SOF+RBV } 24 \text { Weeks } \\
(n=39)\end{array}$ & $\begin{array}{c}\text { Total } \\
(\mathrm{N}=52)\end{array}$ \\
\hline \multicolumn{4}{|l|}{ HCV RNA <15 IU/mL, n/n (\%) } \\
\hline \multicolumn{4}{|l|}{ On treatment } \\
\hline Week 1 & $4 / 13(31)$ & $12 / 39(31)$ & $16 / 52(31)$ \\
\hline Week 2 & $13 / 13(100)$ & $29 / 39(74)$ & $42 / 52(81)$ \\
\hline Week 4 & $13 / 13(100)$ & $36 / 39(92)$ & $49 / 52(94)$ \\
\hline Week 8 & $13 / 13(100)$ & $39 / 39(100)$ & $52 / 52(100)$ \\
\hline Week 12 & $13 / 13(100)$ & $39 / 39(100)$ & $52 / 52(100)$ \\
\hline Week 16 & NA & $39 / 39(100)$ & NA \\
\hline Week 20 & NA & $39 / 39(100)$ & NA \\
\hline Week 24 & NA & $39 / 39(100)$ & NA \\
\hline \multicolumn{4}{|l|}{ After treatment } \\
\hline Week 4 & $13 / 13(100)$ & $39 / 39(100)$ & $52 / 52(100)$ \\
\hline Week 12 (SVR12) & $13 / 13(100)$ & $38 / 39(97)$ & $51 / 52(98)$ \\
\hline $95 \% \mathrm{Cl}$ & $75 \%$ to $100 \%$ & $87 \%$ to $100 \%$ & $90 \%$ to $100 \%$ \\
\hline \multicolumn{4}{|l|}{ Virologic failure, n (\%) } \\
\hline On treatment & 0 & 0 & 0 \\
\hline Relapse & 0 & 0 & 0 \\
\hline Did not complete study, n (\%) & 0 & $1(3)$ & $1(2)$ \\
\hline
\end{tabular}

HCV: hepatitis C virus; NA, not applicable; RBV, ribavirin; SOF, sofosbuvir; SVR12, sustained virologic response 12 weeks after treatment. 
Table 4. Adverse Events and Laboratory Abnormalities

\begin{tabular}{|c|c|c|c|}
\hline & $\begin{array}{c}\text { HCV Genotype } 2 \\
\text { SOF+RBV } \\
12 \text { Weeks } \\
(n=13)\end{array}$ & $\begin{array}{c}\text { HCV Genotype } 3 \\
\text { SOF+RBV } \\
24 \text { Weeks } \\
(n=39) \\
\end{array}$ & $\begin{array}{c}\text { Total } \\
(\mathrm{N}=52)\end{array}$ \\
\hline No. $(\%)$ of patients with any adverse event & $12(92)$ & $30(77)$ & $42(81)$ \\
\hline No. of Grade 3 or 4 adverse events & 0 & $1(3)$ & $1(2)$ \\
\hline No, of patients with a serious adverse event & 0 & 0 & 0 \\
\hline Adverse events leading to discontinuation, $n$ & 0 & 0 & 0 \\
\hline Deaths, $n$ & 0 & 0 & 0 \\
\hline \multicolumn{4}{|c|}{ Adverse events in $\geq 10 \%$ of patients in either treatment group, $n(\%)$} \\
\hline Nausea & $3(23)$ & $11(28)$ & $14(27)$ \\
\hline Headache & $3(23)$ & $9(23)^{\prime}$ & $12(23)$ \\
\hline Asthenia & $1(8)$ & $5(13)$ & $6(12)$ \\
\hline Abdominal pain upper & $2(15)$ & $3(8)$ & $5(10)$ \\
\hline Dizziness & 0 & $4(10)$ & $4(8)$ \\
\hline Oropharyngeal pain & 0 & $4(10)$ & $4(8)$ \\
\hline Diarrhea & $2(15)$ & $1(3)$ & $3(6)$ \\
\hline \multicolumn{4}{|l|}{ Laboratory abnormalities } \\
\hline Bilirubin, Grade 3 (>2.5 to $5.0 \times$ ULN) & 0 & $2(5)$ & $2(4)$ \\
\hline \multicolumn{4}{|l|}{ INR } \\
\hline Grade 3 (>2.0 to $3.0 \times$ ULN) & 0 & $1(3)$ & $1(2)$ \\
\hline Grade $4(>3.0 \times$ ULN) & 0 & $1(3)$ & $1(2)$ \\
\hline White blood cells, Grade $3\left(1,000\right.$ to $\left.<1,500 / \mathrm{mm}^{3}\right)$ & 0 & $1(3)$ & $1(2)$ \\
\hline
\end{tabular}

INR, international normalized ratio of prothrombin time; RBV, ribavirin; SOF, sofosbuvir; ULN, upper limit of normal. 
Table 5. Mean (\%CV) Sofosbuvir and GS-331007 Exposures

\begin{tabular}{lccc}
\hline & $\begin{array}{c}\text { Adolescents } \\
(\mathbf{n}=50)^{\mathrm{a}}\end{array}$ & $\begin{array}{c}\text { Adults } \\
(\mathbf{n}=1695)^{\mathrm{a}}\end{array}$ & $\begin{array}{c}\text { Adolescents vs. Adults } \\
\% \text { GMR (90\% CI) }\end{array}$ \\
\hline Sofosbuvir $^{\mathrm{b}}$ & & & \\
$\mathrm{AUC}_{\text {tau }}(\mathrm{ng} \cdot \mathrm{h} / \mathrm{mL})$ & $1,157(50.6)$ & $1,027(36.5)$ & $109.7(98.4,122.3)$ \\
$\mathrm{C}_{\max }(\mathrm{ng} / \mathrm{mL})$ & $546(53.0)$ & $511(32.5)$ & $98.5(86.7,111.9)$ \\
$\mathrm{GS}_{-331007}$ & & & \\
\hline $\mathrm{AUC}_{\text {tau }}(\mathrm{ng} \cdot \mathrm{h} / \mathrm{mL})$ & $7,969(32.8)$ & $7,123(30.7)$ & $111.5(103.5,120.1)$ \\
$\mathrm{C}_{\max }(\mathrm{ng} / \mathrm{mL})$ & $621(40.7)$ & $582(36.3)$ & $105.5(96.2,115.6)$ \\
\hline
\end{tabular}

${ }^{\mathrm{a}} \mathrm{n}$ subjects with estimable exposure parameters.

${ }^{b} \mathrm{n}=28$ (adolescents) or 838 for adults.

$A U C$, area under the curve; $C_{\max }$, maximum concentration; $C V$, coefficient of variation; $G M R$, geometric mean ratio.

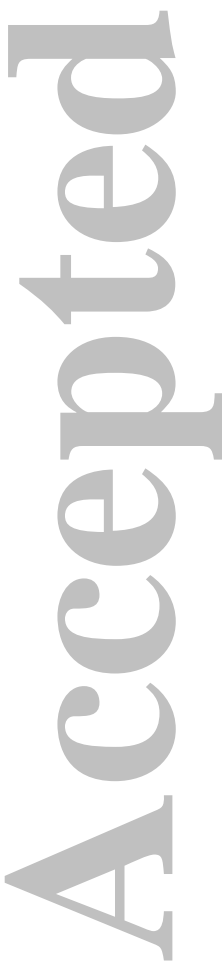




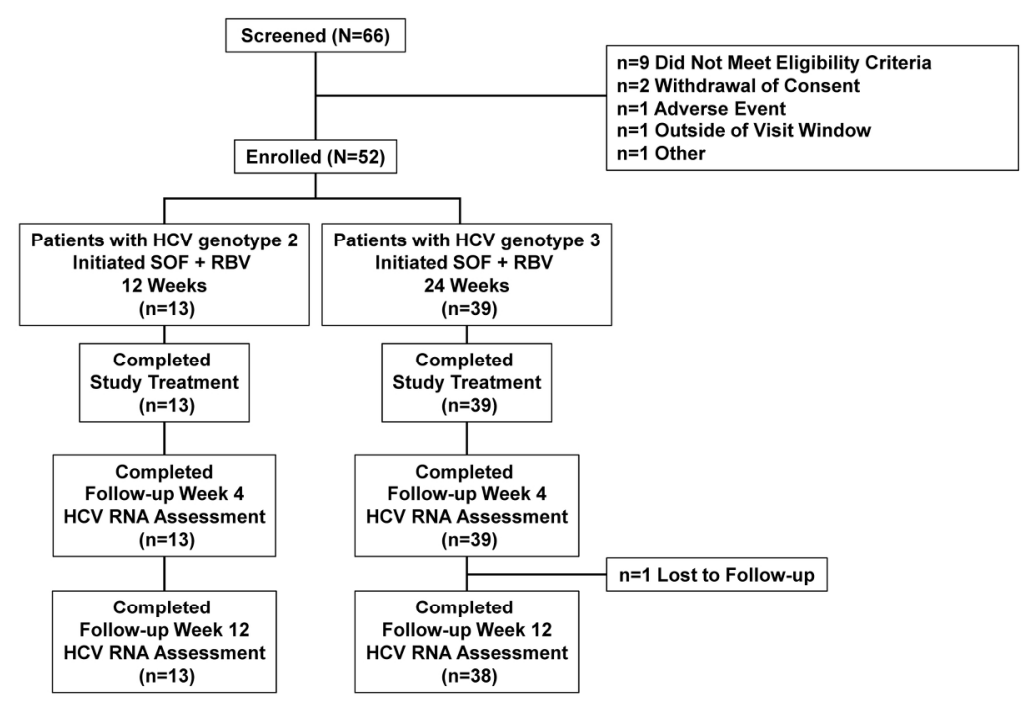

Patient Disposition. HCV, hepatitis C virus; RBV, ribavirin; SOF, sofosbuvir.

$190 \times 107 \mathrm{~mm}(300 \times 300 \mathrm{DPI})$ 


\section{University Library}

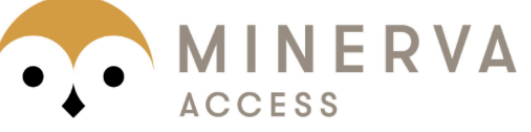

A gateway to Melbourne's research publications

Minerva Access is the Institutional Repository of The University of Melbourne

\section{Author/s:}

Wirth, S;Rosenthal, P;Gonzalez-Peralta, RP;Jonas, MM;Balistreri, WF;Lin, C-H;Hardikar, W;Kersey, K;Massetto, B;Kanwar, B;Brainard, DM;Shao, J;Svarovskaia, E;Kirby, B;Arnon, R;Murray, KF;Schwarz, KB

Title:

Sofosbuvir and Ribavirin in Adolescents 12-17 Years Old With Hepatitis C Virus Genotype 2 or 3 Infection

\section{Date:}

2017-10-01

\section{Citation:}

Wirth, S., Rosenthal, P., Gonzalez-Peralta, R. P., Jonas, M. M., Balistreri, W. F., Lin, C. -H., Hardikar, W., Kersey, K., Massetto, B., Kanwar, B., Brainard, D. M., Shao, J., Svarovskaia, E., Kirby, B., Arnon, R., Murray, K. F. \& Schwarz, K. B. (2017). Sofosbuvir and Ribavirin in Adolescents 12-17 Years Old With Hepatitis C Virus Genotype 2 or 3 Infection. HEPATOLOGY, 66 (4), pp.1102-1110. https://doi.org/10.1002/hep.29278.

Persistent Link:

http://hdl.handle.net/11343/293371 